\title{
Self-reported maternal handwashing knowledge and behaviours observed in a rural hospital in Pakistan
}

\author{
Shehnoor Azhar, , Madeha Faisal $^{3}$ and Arifa Aman ${ }^{4}$
}

${ }^{1}$ Department of Public Health, University of Health Sciences, Khayaban e Jamia Punjab, Lahore, Pakistan ${ }^{2}$ Department of Public Health \& Clinical Medicine, University of Granada Spain. (Correspondence to: Shehnoor Azhar: Shehnoor.azhar@gmail.com) 32Department of Paediatrics, Sughra Shafi Medical Complex, Narowal, Pakistan. ${ }^{4}$ Department of Physiology, Lahore Medical \& Dental College, Lahore, Pakistan.

\begin{abstract}
Background: Under-5 mortality remains high in developing nations despite decades of multilateral cooperation to reduce it. Diarrhoea contributes up to $15 \%$ of all mortality in this age group. Frequently reported barriers include poor hygiene, lack of sanitation facilities, and negligible public health education on the issue. Interventions such as Water, Sanitation, and Hygiene (WASH) could complement modern public health approaches with renewed vigour in wake of SARS-CoV-II (COVID-19).

Aims: We sought to assess maternal hand hygiene and ability to prepare oral rehydration solution at home.

Methods: In addition to the ability to prepare oral rehydration solution at home, this cross-sectional study, carried out at the Sughra Shafi Medical Complex, Narowal during 2017, compared knowledge, attitudes and behaviours of mothers of children with diarrhoea to those shoes children did not have diarrhoea.

Results: 511 (48\%) children < 5 years were diagnosed with diarrhoea irrespective of household location. Among 1065 accompanying mothers recruited for this study, only 130 (12\%) were able to prepare ORS at home and 288 (27\%) qualified as regular hand-washers according to the criteria. Just over half of the respondents consumed untreated water supplied via a nearby canal. Almost $80 \%$ of neighbourhoods lacked waste collection.

Conclusion: These findings informed management of frequent child diarrhoea cases presented at the hospital with locally relevant preventive knowledge. They are also expected to be useful in educating mothers on regular handwashing and the preparation of ORS as home-based interventions.

Keywords: childhood diarrhoea, WASH, ORS, hygiene, sanitation

Citation: Azhar S; Faisal M; Aman A. Self-reported maternal handwashing knowledge and behaviours observed in a rural hospital in Pakistan. East Mediterr Health J. 2021;27(7):665-671. https://doi.org/10.26719/emhj.20.078

Received: 28/08/19; accepted: 23/12/19

Copyright (c) World Health Organization (WHO) 2021. Open Access. Some rights reserved. This work is available under the CC BY-NC-SA 3.0 IGO license (https://creativecommons.org/licenses/by-nc-sa/3.o/igo)
\end{abstract}

\section{Introduction}

Sustainable development in the World Health Organization (WHO) Region for the Eastern Mediterranean (EMR) has been held back by familiar shortcomings $(1,2)$. A recent review of the Millennium Development Goals (MDGs) depicted the EMR as making patchy progress instead of applying coherent national planning to improve living standards across the board. It cited known limitations to sector-specific development practised during the 2oth century as evident in several countries where the burden of childhood diarrhoea ( $<5$ years of age) has persisted despite decades of multilateral engagement for its eradication $(3,4)$. Analyses of these missed opportunities identified 2 interrelated and well-known factors being ignored. First, the continuously poor state of local sanitation in relation to prevailing diarrhoea. Second, disseminating knowledge of this relationship as a policy. Under $5(<5)$ diarrhoea is now the second biggest killer, causing $15 \%$ of total mortality in this age group besides leaving survivors with an array of lifelong disabilities, including malnutrition, developmental disorders, and enteropathies (4-6). Many communities in sub-Saha- ran Africa have leveraged the aforementioned factors to achieve nearly $66 \%$ reduction in diarrhoea-attributed child mortality $(3,7)$. Within the EMR, "low-performing countries" face an uphill struggle $(8,9)$. Tens of millions of children remain at risk of preventable infectious diseases originating from compromised sanitation and hygiene at all levels $(10,11)$. Modern public health paradigms must not ignore, but build further upon, traditional development approaches such as Water, Sanitation and Hygiene (WASH), particularly where basic community services are degraded or nonexistent.

Like many countries in the Region, Pakistan has a long history of implementing the global agenda for diarrhoea control (12). Despite hosting the 3rd International Association for Maternal and Neonatal Health Congress in Lahore to interventions like Control of Diarrhoea Disease and exploring various local treatment options, the country nevertheless continues to experience high $<5$ mortality owing to diarrhoeal diseases (13-15). Recently introduced community-driven care models have relied on building coalitions to get greater in-depth perspectives on household hygiene practices $(8,16)$. In 2015, the Expert Review Group ranked Pakistan among 
the countries unlikely to achieve MDGs 4 and 5 on the back of structural factors such as inadequate maternal and child care, haphazard development and population displacements $(1,10,17)$. However, some countries in the Region, e.g. Oman and Lebanon, have already met the health benchmarks.

Against this backdrop, we carried out this study at the paediatric department of a philanthropic teaching hospital in the eastern rural district of Narowal (Punjab, Pakistan). We sought to assess maternal hand hygiene and the ability to prepare oral rehydration solution (ORS) at home; these are considered the most impactful prevention and timely management practices for < 5 diarrhoea $(18,19)$. We also contextualized maternal knowledge and behaviours with sociodemographic details along with household status and neighbourhood sanitation.

Our findings were expected to inform institutional protocol for prevention of child diarrhoea with the local situation so that staff could better educate caregivers particularly in wake on ongoing SARS-CoV-II (COVID-19). In addition, the study was expected to generate interest in this topic for future researchers at the institution.

\section{Methods}

This cross-sectional study recruited all mothers that accompanied children $<5$ years of age at the hospital during July-September 2017. To assess the association of diarrhoeal disease with location (rural or urban) and self-reported maternal ability to prepare ORS, 2 study groups were established: mothers of children with diarrhoeal illness and mothers of children with non-diarrhoeal illnesses. For clinical diagnosis of child diarrhoea, the WHO definition was adopted: "passage of 3 or more loose or liquid stools per day (or more frequent passage than is normal for the individual)" (20).

In the absence of any reliable data from which to establish a baseline, sample-size calculations and the feasibility plan were based on a pilot study involving 65 mothers at an urban teaching hospital $(21,22)$, where $22 \%$ of children of regularly hand-washing mothers presented with diarrhoea compared with $30 \%$ of the children of non-hand-washers.

Using OpenEpi, we calculated a total sample size of 1008 at 95\% confidence interval, power of 80 , and odds ratio 1.5 . An additional $5 \%$ were recruited to arrive at final sample of 1065. Pilot testing also refined the response structure so that the analytical strategy could better test maternal knowledge of ORS preparation as being protective against child diarrhoea $(21,22)$. Consecutive sampling was conducted to collect data during each of the 3 daily shifts including weekends.

When a child initially presented to the paediatric department with a complaint (s)he was managed according to the established treatment protocol. Later, accompanying mothers were contacted for participation. The rationale of the study was explained to them before recruitment and they were asked to sign an informed consent form printed in the local language. The mothers were then provided with a selfadministered questionnaire in the local language. About 1090 accompanying mothers were invited to the survey out of which 1065 volunteered to participate (response rate $97.7 \%$ ). Those who could not read and write were given details of the study orally by the investigator in the presence of family members. Informed consent was obtained as a thumb impression on the consent form. They were then interviewed by investigators in the local language to complete the questionnaire. Mothers in distress owing to their sick child and those declining to participate were excluded. All participating mothers were informed that their personal information would be confidential and kept for the period of 5 years. Afterwards, data in all forms would be shredded.

Maternal handwashing frequency was one of the key constructs of this study. Regular handwashing was defined in this study as performed with soap a minimum of 14 times a day after "critical moments" $(23,24)$. These were reported as daily cultural routines comprising women cooking 3 meals and subsequently eating with household members, cleaning up and changing baby diapers, and responding to calls of nature.

The study tool was pre-tested for content validity and reliability. It was drafted in the local language according to the conceptual framework (Figure 1). The initial draft was shared with 2 national experts for comments on validity. Their feedback was incorporated to further categorize response options to match the analytical strategy. Once approved by the reviewers, the final questionnaire comprised 33 response options divided into 5 sections: demographic details; maternal knowledge and behaviours; state of neighbourhood sanitation; household water supply and usage; and access to local lady health workers (LHWs). It was then pilot-tested for

\section{Figure 1 Conceptual framework to observe contextualized prevalence of diarrhoea in children under 5 years in a rural hospital in Pakistan}

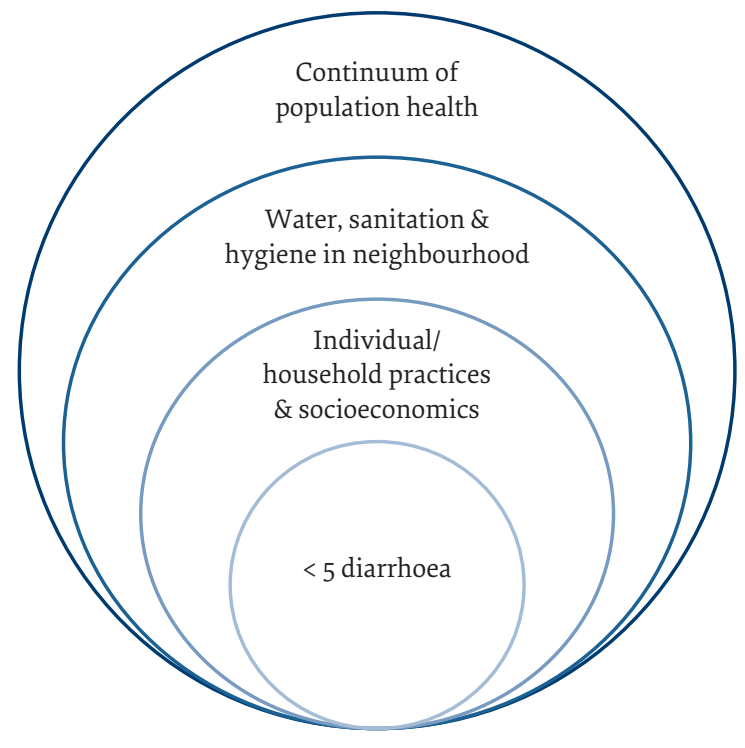


reliability in another hospital. The decision on its use in the study setting was made on computing the alpha coefficient $\sim 0.77$. The final draft was adopted following 94\% inter-examiner reliability.

All entries were done by a trained data entry intern under the supervision of the primary investigator. Stata, version 14, was used for analyses. Inferential statistics were computed to test the hypotheses for the 2 study groups while descriptive statistics were presented for the entire study sample for highlighting key findings with clarity. The ethical review committee at the constituent medical college approved this study.

\section{Results}

Demographic characteristics and the sanitation status of our sample are shown in Table 1. About one third of responding mothers had completed secondary school education. The most frequent source of household water supply was a nearby canal $(59.1 \%)$. Although $93.7 \%$ of respondents reported cleaning their household water storage tanks at least once a year, less than half $(44.5 \%)$ treated water before drinking and/or cooking.

\begin{tabular}{|c|c|c|}
\hline Characteristic & No. & $\%$ \\
\hline Age of child & & \\
\hline Neonate & 44 & 4.1 \\
\hline Infant & 601 & 56.4 \\
\hline $2-5$ years & 420 & 39.4 \\
\hline Maternal education & & \\
\hline Never attended & 104 & 9.8 \\
\hline Incomplete secondary school & 324 & 30.4 \\
\hline Completed secondary school & 352 & 33.1 \\
\hline College degree & 236 & 22.2 \\
\hline University degree & 49 & 4.6 \\
\hline Residence $^{*}$ & & \\
\hline Urban & 201 & 19.0 \\
\hline Rural & 855 & 80.3 \\
\hline Annual cleaning of household sto & & \\
\hline Yes & 998 & 93.7 \\
\hline No & 67 & 6.3 \\
\hline Source of household water supply & & \\
\hline Tube well & 9 & 0.9 \\
\hline Personal boring & 382 & 35.9 \\
\hline Nearby canal & 629 & 59.1 \\
\hline Don't know & 45 & 4.2 \\
\hline Drinking water treated & & \\
\hline Yes & 474 & 44.5 \\
\hline No & 591 & 55.5 \\
\hline
\end{tabular}

${ }^{{ }^{*} \text { Some data missing. }}$
Table 2 Frequency of conditions reported among children $<5$ years $(n=1065)$ to paediatric emergency at a rural hospital in Pakistan, 2017

\begin{tabular}{lcc} 
Condition & No. & $\%$ \\
\hline Diarrhoea & 511 & 48.0 \\
Anaemia (weakness) & 202 & 19.0 \\
Acute respiratory infections & 170 & 16.0 \\
Skin lesions and trauma & 105 & 9.9 \\
Miscellaneous & 77 & 7.3 \\
\hline
\end{tabular}

Of the 1065 children $<5$ years old presenting at the paediatric department with their mothers, a total of $511(48.0 \%)$ were diagnosed with diarrhoea (Table 2) according to the WHO definition. After diarrhoea, anaemia or weakness was the second most common presenting complaint $(202,19.0 \%)$, confirmed by complete blood count.

Despite the majority of mothers knowing the local LHW personally (data not shown), only 130 (12.2\%) were able to prepare ORS at home (Table 3); among these, 69.2\% stated the local LHW was their main information source. The majority of the children $(80.3 \%)$ were from rural areas (verified from hospital records) (Table 1) but the incidence of diarrhoea was independent of residence $(P$ $>0.05$ ). The median household income of our sample was rupees 20000 (US\$208) (statistics not included). Almost $70 \%$ of respondents spent up to $2 \%$ of monthly household income on handwashing soap but only $64 \%$ stated they were willing to pay up to $2 \%$ (Table 4). However, $33.6 \%$ were willing to pay up to $5 \%$ of monthly household income on soap compared to $28.6 \%$ who reported actually spending this amount.

Almost $95 \%$ of respondents had access to at least one household toilet with running water (Table 5) but only $20.9 \%$ lived in neighbourhoods with a waste collection system. In accordance with our definition, $27.1 \%$ of mothers self-reported as regular hand-washers. Specifically, $17.6 \%$ reported washing hands with soap following each daily toilet visit and before cooking and eating.

\section{Discussion}

In this study we compared mothers of children $<5$ years with diarrhoea to those whose children did not have diarrhoea and found little difference in hand hygiene knowledge, attitudes and practices in relation to sociodemographic details, the status of the household and neighbourhood sanitation.

Childhood diarrhoea was the most frequent condition among children presenting at the study hospital throughout the 3 months of data collection. Extremely low maternal knowledge of ORS preparation $(12 \%)$ and the predominance of rural representation $(81 \%)$ in our sample made it unlikely to meaningfully relate these 2 factors with the occurrence of childhood diarrhoea. The study hypotheses could have been better framed if 


\begin{tabular}{|c|c|c|c|c|}
\hline $\begin{array}{l}\text { Table } 3 \text { Source of info } \\
\text { preparation of oral re } \\
\text { of sick children }(n=1\end{array}$ & $\begin{array}{l}\text { natio } \\
\text { ydrati } \\
\text { ) in a }\end{array}$ & $\begin{array}{l}\text { knou } \\
\text { Ition } 1 \\
\text { ospita }\end{array}$ & $\begin{array}{l}\text { Ige c } \\
\text { orte }\end{array}$ & $\begin{array}{l}\text { others } \\
2017\end{array}$ \\
\hline Information source & $\begin{array}{r}\text { Mo } \\
\text { childre } \\
\text { diarrh } \\
\text { ( }\end{array}$ & $\begin{array}{l}\text { s of } \\
\text { th non- } \\
\text { illness } \\
\text { 3) }\end{array}$ & $\begin{array}{r}\text { Mo } \\
\text { child } \\
\text { dia } \\
\text { i } \\
\text { ( }\end{array}$ & $\begin{array}{l}\text { s of } \\
\text { with } \\
\text { eal } \\
\text { s } \\
\text { 7) }\end{array}$ \\
\hline & No. & $\%$ & No. & $\%$ \\
\hline Knows by profession & 2 & 3.1 & 3 & 4.4 \\
\hline TV/radio & 12 & 19.0 & 18 & 26.8 \\
\hline Hospital staff & 2 & 3.1 & 3 & 4.4 \\
\hline Health worker & 47 & 74.6 & 43 & 64.1 \\
\hline
\end{tabular}

a prior baseline for these variables had been available. Nevertheless, our findings might serve as baseline for future research on this topic. In fact, our results identified important thematic areas in health service delivery for researchers since the majority of respondents knew their local LHW personally but were unable to prepare ORS at home. Despite this reported disconnect, LHWs were the most frequent source of information on ORS preparation among those who knew how to do it. Only 5 respondents mentioned hospital staff (physicians, nurses) as their informers on ORS preparation. These findings met the study objective to assess the need for an updated protocol at this hospital to contextualize preventive management of child diarrhoea with household practices and the state of sanitation in the neighbourhood. Follow-up studies are strongly recommended in this hospital to observe the intended impact of educating caregivers/ mothers in relation to future caseloads of $<5$ diarrhoea. Institutionalized information on household and neighbourhood factors could partly offset chronic gaps in rural health for non-diarrhoeal illnesses too $(17,25)$.

We identified the frequency of non-diarrhoeal conditions that could be further studied for corresponding strategies. With the very low overall knowledge of ORS preparation reported above, our results showed both radio and television as being the most common source of information on ORS preparation (statistics not included), second only to hospital staff. These findings could encourage greater use of broadcast media to improve health literacy in similar settings $(26,27)$.

Health and hygiene behaviours represent an emerging frontier of public health that was touched upon here $(1,28)$. Irrespective of nearly all respondents having access to a household toilet equipped with a flush system, less than $50 \%$ reported washing hands regularly after toilet visits and only $18 \%$ reported maintaining hand hygiene for all of the 3 daily activities. This warrants better understanding of complex behavioural pathways mentioned in the Global Enteric Multicentre Study that aimed to devise policy levers to cut the spread of diarrhoeal illness through curbing oral-faecal transmission (28). In some south Asian countries (Bangladesh, India, Pakistan), it was reported that over $93 \%$ households had toilets yet in a significant proportion, human faeces were visible within the house or adjoining yard (28). A study from the hilly region of Swat in Pakistan also reported substantial faecal contamination of drinking water sources (29). Oralfaecal transmission contributes widely to nearly 2 billion annual diarrhoeal episodes in children $<5$ worldwide.

In our sample, about one-third of the mothers stated they were willing to pay up to $5 \%$ of monthly household income on soap and $28.6 \%$ reported actually doing so. Future research should assess the affordability of soap in low-resource, but water-sufficient, communities and the role of income as barrier or facilitator of handwashing. It is important to highlight the relationship between household income and handwashing so that this can be promoted in such communities. Our findings have suggested that a smaller household income is related to a lower willingness to pay for soap.

As is commonplace in global epidemiological data, developing nations carry a disproportionate burden of diarrhoea and its aftermath with chronic institutional incapacities $(24,30)$. It has been feared that continued lack of investment in public services coupled with higher population growth rates could reverse the health gains of past decades in developing countries. These projections warrant a comprehensive response to control oralfaecal spread through improving the quality of existing research into health behaviours. With the abundant data on development history now available for many countries and regions, traditional approaches such as WASH could

Table 4 Comparison of monthly household income spent on soap and willingness to pay for it (reported by mothers of children under 5 years presenting to a rural paediatric department in Pakistan), 2017

\begin{tabular}{lcccccc}
$\begin{array}{l}\text { Willingness to pay for soap } \\
\text { as percentage of monthly } \\
\text { household income (\%) }\end{array}$ & $\leq \mathbf{1 \%}$ & $\leq \mathbf{2 \%}$ & $\leq \mathbf{5} \%$ & $\leq \mathbf{1 0} \%$ & $\mathbf{1 0} \%$ & Total \\
\hline$\leq 1$ & $263(25.2)$ & $12(1.1)$ & 0 & 0 & 0 & $275(26.4)$ \\
$>1$ to 2 & $49(4.7)$ & $328(31.5)$ & $14(1.3)$ & $1(0.09)$ & 0 & $392(37.6)$ \\
$>2$ to 5 & 0 & $64(6.1)$ & $279(26.8)$ & $6(0.5)$ & $1(0.09)$ & $350(33.6)$ \\
$>5$ to 10 & 0 & $1(0.09)$ & $3(0.2)$ & $13(1.2)$ & $1(0.09)$ & $18(1.7)$ \\
$>10$ & $1(0.09)$ & $2(0.1)$ & $2(0.1)$ & 0 & 20 & $05(0.4)$ \\
Total & $313(30)$ & $407(39.1)$ & $298(28.6)$ & $20(1.9)$ & $2(0.1)$ & 1040 \\
\hline
\end{tabular}




\begin{tabular}{|c|c|c|}
\hline \multicolumn{3}{|c|}{$\begin{array}{l}\text { Table } 5 \text { Daily frequency of handwashing with soap and } \\
\text { sanitation status among mothers }(n=1065) \text { of children } \\
\text { presenting to a rural hospital in Pakistan, } 2017\end{array}$} \\
\hline Factor & No. & $\%$ \\
\hline \multicolumn{3}{|l|}{ Maternal handwashing practice } \\
\hline After toilet use & 488 & 45.8 \\
\hline Toilet use \& before meals & 384 & 36.1 \\
\hline After toilet, before meals, before cooking & 187 & 17.6 \\
\hline Infrequent or minimal & 06 & 0.6 \\
\hline \multicolumn{3}{|l|}{ Household toilet with water tank \& flush } \\
\hline Yes & 1005 & 94.4 \\
\hline No & 60 & 5.6 \\
\hline \multicolumn{3}{|l|}{$\begin{array}{l}\text { Frequency of self-reported handwashing with } \\
\text { soap }\end{array}$} \\
\hline$\leq 6$ times daily & 125 & 11.7 \\
\hline$<14$ times daily & 651 & 61.1 \\
\hline$\leq 14$ times daily & 289 & 27.1 \\
\hline \multicolumn{3}{|l|}{ Neighbourhood waste collection system present } \\
\hline Yes & 220 & 20.9 \\
\hline No & 830 & 78.5 \\
\hline Don't know & 09 & 0.9 \\
\hline
\end{tabular}

find innovative implementation methods for greater community impact $(3,31)$.

Our sample was limited by time and catchment area served by a solitary teaching hospital; thus we excluded analysis of water, hygiene and sanitation in relation to the prevalence of $<5$ diarrhoea according to income group. This may have informed a useful social determinants perspective. Analytical study designs could provide these missing details since low levels of neighbourhood waste collection and widespread consumption of untreated canal water are often linked to $<5$ diarrhoea $(3,32)$. For such undertakings, far more resources and experience in the development sector would have been required such as reflected in large household surveys carried out by international organizations (33). Rates of child diarrhoea reported here could also be inflated due to the concurring monsoon, which creates conditions favourable for the transmission and spread of infections. At facility level, year-round disease registries are suggested as a local surveillance tool. In addition, periodic assessments of staff knowledge and attitudes on prevailing diseases could identify professional training needs for better case management $(34,35)$. Finally, the minimal intergroup differences observed in this study necessitated the presentation of statistics for the entire sample to avoid meaningless comparisons and vague interpretations.

\section{Conclusion}

Child diarrhoea was the major reason for hospital admission irrespective of rural or urban residence. Despite residing in neighbourhoods that lacked solid waste collection, few mothers practiced regular hand hygiene. Similarly, maternal knowledge on preparing ORS was very limited despite familiarity with local LHWs. Untreated canal water was widely consumed in households. This information could be useful not only in better treatment for child diarrhoea but also to enable hospital staff to contextualize WASH as a tool for education on prevention for caregivers. Simultaneous studies on impact must be undertaken.

\section{Acknowledgement}

We wish to thank all participating families and the staff and administration at Sughra Shafi Medical Complex/Sahara Medical College, Narowal.

Funding: Secretarial support was given by Sughra Shafi Medical Complex, Narowal.

Competing interests: None declared.

\section{Connaissances autodéclarées des mères en matière de lavage des mains et comportements observés dans un hôpital rural au Pakistan}

\section{Résumé}

Contexte: La mortalité des moins de 5 ans reste élevée dans les pays en développement malgré les efforts de coopération multilatérale déployés depuis plusieurs décennies pour la réduire. Jusqu'à $15 \%$ de la mortalité totale dans cette tranche d'âge est liée à la diarrhée. Les obstacles fréquemment signalés comprennent les mauvaises conditions d'hygiène, le manque d'installations d'assainissement et l'insuffisance des efforts de sensibilisation sur la question. Des interventions dans le domaine de l'eau, de l'assainissement et de l'hygiène (WASH) pourraient venir compléter les approches modernes de santé publique avec une vigueur renouvelée afin de lutter contre le SARS-COV-2 (COVID-19).

Objectifs : Nous avons cherché à évaluer l'hygiène des mains des mères et leur capacité à préparer une solution de réhydratation orale (SRO) à domicile.

Méthodes: Outre cette capacité, la présente étude transversale, qui a été réalisée en 2017 au complexe médical Sughra Shafi, à Narowal, et se proposait de comparer les connaissances, les attitudes et les comportements des mères d'enfants souffrant de diarrhée à celles dont les enfants n'en souffraient pas. 
Résultats : Sur les enfants de moins de 5 ans, 511 (48\%) souffraient de diarrhée, quel que soit le lieu du foyer. Des 1065 mères accompagnantes recrutées pour la présente étude, seules 130 (12\%) ont été en mesure de préparer une SRO à domicile et $288(27 \%)$ ont satisfait aux critères leur permettant d'être reconnues comme pratiquant un lavage de mains régulier. Un peu plus de la moitié des répondantes consommaient l'eau non traitée d'un canal situé à proximité. Il n'y avait pas de collecte de déchets dans près de $80 \%$ des quartiers.

Conclusion : Ces résultats seront utiles à la prévention au niveau local et permettront d'améliorer la prise en charge des cas fréquents de diarrhée infantile observés dans cet hôpital. On s'attend également à ce qu'ils soient utiles pour éduquer les mères au lavage régulier des mains et à la préparation des SRO à domicile.

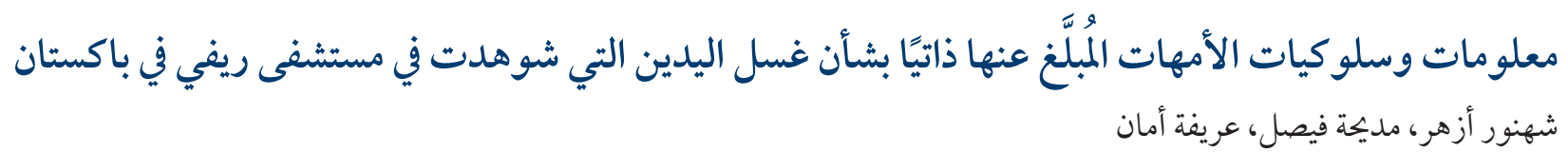

الخلفية: لا يز ال معدل وفيات الأطفال دون سن الخامسة مرتفعًا في البلدان النامية على الرغم من مرور عقود من التعاون المتعدد الأطر اف سعيًا

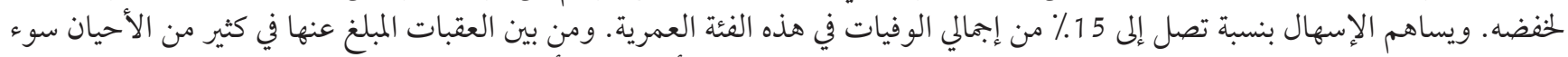

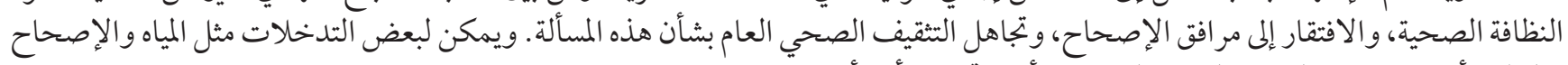

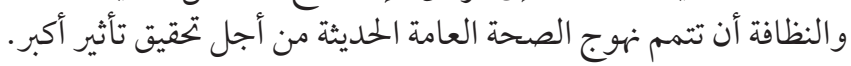
الأهداف: هدفت هذه الدراسة إلى تقييم نظافة اليدين لدى الأمهات وقدرتهن على تحضير محلول الإمهاء الفموي في المنزل. طرق البحث: بالإضافة إلى القدرة على تحضير محاليل الإمهاء الفموي في المنزل، قارنت هذه الدراسة المقطعية، التي أجريت في مجمع (اصخرة

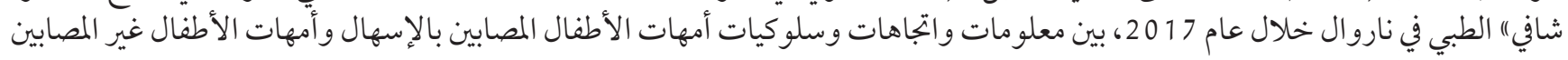

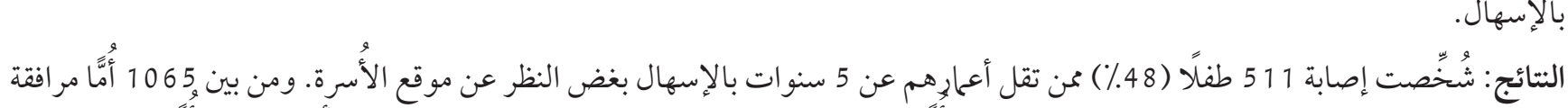

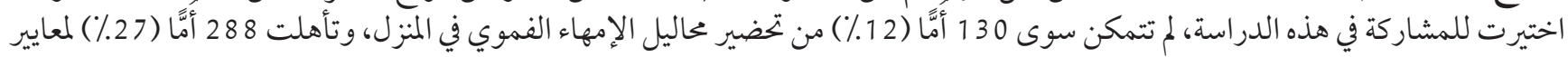

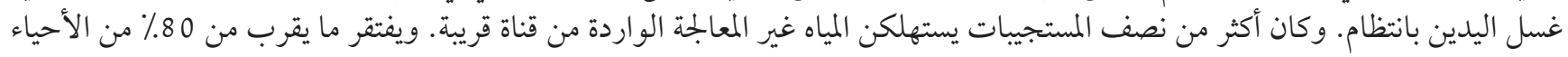
السكنية إلى جمع النفايات.

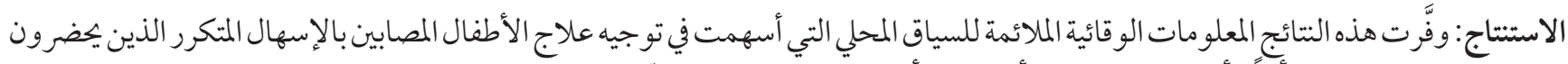

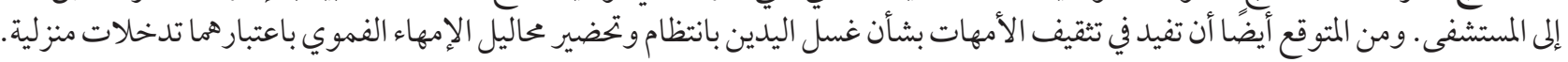

\section{References}

1. Akseer N, Kamali M, Husain S, Mirza M, Bakhache N, Bhutta ZA. Strategies to avert preventable mortality among mothers and children in the Eastern Mediterranean Region: new initiatives, new hope. East Mediterr Health J. 2015;21(5):361-73. doi:10.26719/2015.21.5.361

2. Khalil I, Colombara DV, Forouzanfar MH, Troeger C, Daoud F, Moradi-Lakeh M, et al. Burden of diarrhea in the Eastern Mediterranean Region, 1990-2013: findings from the Global Burden of Disease Study 2013. Am J Trop Med Hyg, 2016;95(6):1319-29. doi:10.4269/ajtmh.16-0339

3. Darvesh N, Das JK, Vaivada T, Gaffey MF, Rasanathan K, Bhutta ZA, et al., Water, sanitation and hygiene interventions for acute childhood diarrhea: a systematic review to provide estimates for the Lives Saved Tool. BMC Public Health. 2017;17(Suppl. 4):776. doi:10.1186/s12889-017-4746-1

4. Ashraf S, Huque MH, Kenah E, Agboatwalla M, Luby SP. Effect of recent diarrhoeal episodes on risk of pneumonia in children under the age of 5 years in Karachi, Pakistan. Int J Epidemiol. 2013;42(1):194-200. doi:10.1093/ije/dys233

5. Bhutta ZA, Guerrant RL, Nelson CA 3rd. Neurodevelopment, Nutrition, and Inflammation: The Evolving Global Child Health Landscape. Pediatrics. 2017;139(Suppl. 1):S12-S22. doi:10.1542/peds.2016-2828D

6. Bhutta ZA, Molla AM, Issani Z, Badruddin S, Hendricks K, Snyde JD. Dietary management of persistent diarrhea: comparison of a traditional rice-lentil based diet with soy formula. Pediatrics. 1991;88(5):1010-8.

7. Colston JM, Ahmed AMS Soofi SB, Svensen E, Haque R, Shrestha, et al., Seasonality and within-subject clustering of rotavirus infections in an eight-site birth cohort study. Epidemiol Infect. 2018;146(6):688-97. doi:10.1017/S0950268818000304

8. Aftab W, Shipton L, Rabbani F, Sangrasi K, Perveen S, Zahidie A, et al., Exploring health care seeking knowledge, perceptions and practices for childhood diarrhea and pneumonia and their context in a rural Pakistani community. BMC Health Serv Res. 2018;18(1):44. doi:10.1186/s12913-018-2845-z

9. Azmatullah A, Qamar FN, Thaver D, Zaidi AK, Bhutta ZA. Systematic review of the global epidemiology, clinical and laboratory profile of enteric fever. J Glob Health. 2015;5(2):020407. doi:10.7189/jogh.05.020407 
10. Bhutta ZA, Das JK. Global burden of childhood diarrhea and pneumonia: what can and should be done? Pediatrics. 2013;131(4):634-6. doi:10.1542/peds.2012-3737

11. Hasan MM, Richardson A. How sustainable household environment and knowledge of healthy practices relate to childhood morbidity in South Asia: analysis of survey data from Bangladesh, Nepal and Pakistan. BMJ Open. 2017;7(6):e015019. doi:10.1136/ bmjopen-2016-015019.

12. Declaration of Lahore of the IIIrd International Congress on Maternal and Neonatal Health. Malays J Reprod Health. 1987;5(2):111-6. PMID:12315182

13. New programme review process for diarrhoeal disease control. World Health Forum. 1994;15(1):96-8. PMID:8141993

14. International Working Group on Persistent Diarrhoea. Evaluation of an algorithm for the treatment of persistent diarrhoea: a multicentre study. Bull World Health Organ. 1996;74(5):479-89. PMID:9002328

15. IV Commonwealth Congress on Diarrhoea and Malnutrition. Karachi, Pakistan. Meeting of the Commonwealth Association of Pediatric Gastroenterology and Nutrition. November 21-24, 1997. Abstracts. J Pediatr Gastroenterol Nutr. 1998;27(2):242-68. PMID:9841262

16. Bawankule R, Singh A, Kumar K, Shetye S. Does measles vaccination reduce the risk of acute respiratory infection (ARI) and diarrhea in children: a multi-country study? PLoS One. 2017;12(1):e0169713. doi:10.1371/journal.pone.0169713

17. Bhutta ZA, Zipursky A, Wazny K, Levine MM, Black RE, Bassani DG, et al. Setting priorities for development of emerging interventions against childhood diarrhoea. J Glob Health. 2013;3(1):010302. doi:10.7189/jogh.03.010302

18. Quadri F, Nasrin D, Khan A, Bokhari T, Tikmani SS, Nisar MI, et al. Health care use patterns for diarrhea in children in low-income periurban communities of Karachi, Pakistan. Am J Trop Med Hyg. 2013;89(1 Suppl.):49-55. doi:10.4269/ajtmh.12-0757

19. Das JK, Hadi YB, Salam RA, Hoda M, Lassi ZS, Bhutta ZA. Fly control to prevent diarrhoea in children. Cochrane Database Syst Rev. 2018;12:CD011654. doi:10.1002/14651858

20. Levine GA, Walson JL, Atlas HE, Lamberti LM, Pavlinac PB. Defining pediatric diarrhea in low-resource settings. J Pediatric Infect Dis Soc. 2017;6:289-93.

21. McLaren CE, Chen WP, O'Sullivan TD, Gillen DL, Su MY, Chen JH, et al. Sample size and power determination when limited preliminary information is available. BMC Med Res Methodol. 2017;17:75. https://doi.org/10.1186/s12874-017-0329-1

22. Paródi Lopez N, Wallerstedt SM. Quality of prescribing in older people from a broad family physician perspective: a descriptive pilot study. BMJ Open. 2019;9(6):e027290. doi:10.1136/bmjopen-2018-027290

23. Dagne H, Bogale L, Borcha M, Tesfaye A, Dagnew B. Hand washing practice at critical times and its associated factors among mothers of under five children in Debark town, northwest Ethiopia, 2018. Ital J Pediatr. 2019;45:120.doi:10.1186/s13052-019-0713-z

24. Taddese AA, Dagnew B, Dagne H, Andualem Z. Mother's handwashing practices and health outcomes of under-five children in northwest Ethiopia. Pediatric Health Med Ther. 2020;11:101-8. doi:10.2147/PHMT.S238392

25. Alam MM, Khurshid A, Shaukat S, Suleman RM, Sharif S, et al. Epidemiology and genetic diversity of rotavirus strains in children with acute gastroenteritis in Lahore, Pakistan. PLoS One. 2013;8(6):e67998. doi:10.1371/annotation/68a1d471-b3b1-45e7-9b81 - d242fic2oadi

26. Bowen A, Agboatwalla M, Ayers T, Tobery T, Tariq M, Luby SP. Sustained improvements in handwashing indicators more than 5 years after a cluster-randomised, community-based trial of handwashing promotion in Karachi, Pakistan. Trop Med Int Health. 2013;18(3):259-67. doi:10.1111/tmi.12046

27. Luby SP, Agboatwalla M, Feikin DR, Painter J, Billhimer W, Altaf A, et al. Effect of handwashing on child health: a randomised controlled trial. Lancet. 2005;366(9481):225-33. PMID:16023513

28. Baker KK, O’Reilly CE, Levine MM, Kotloff KL, Nataro JP, Ayers TL, et al. Sanitation and hygiene-specific risk factors for moderate-to-severe diarrhea in young children in the Global Enteric Multicenter Study, 2007-2011: case-control study. PLoS Med. 2016;13(5):e1002010. doi:10.1371/journal.pmed.1002010

29. Khan K, Lu Y, Saeed MA, Bilal H, Sher H, Khan H., et al. Prevalent fecal contamination in drinking water resources and potential health risks in Swat, Pakistan. J Environ Sci (China). 2018;72:1-12. doi:10.1016/j.jes.2017.12.008

30. Bitew BD, Woldu W, Gizaw Z. Childhood diarrheal morbidity and sanitation predictors in a nomadic community. Ital J Pediatr 2017;43:91. doi:10.1186/s13052-017-0412-6

31. Bawa S, McNab C, Nkwogu L, Braka F, Obinya E, Galway M, et al. Using the polio programme to deliver primary health care in Nigeria: implementation research. Bull World Health Organ. 2019;97(1):24-32. doi:10.2471/BLT.18.211565

32. Chavasse D, Ahmad N, Akhtar T. Scope for fly control as a diarrhoea intervention in Pakistan: a community perspective. Soc Sci Med. 1996;43(8):1289-94. PMID:8903134

33. Fikree FF, Azam SI, Berendes HW. Time to focus child survival programmes on the newborn: assessment of levels and causes of infant mortality in rural Pakistan. Bull World Health Organ. 2002;80(4):271-6. PMID:12075362

34. Bhutta TI, Balchin C. Assessing the impact of a regulatory intervention in Pakistan. Soc Sci Med. 1996;42(8):1195-202. doi:10.1016/0277-9536(95)00392-4

35. Lavis JN, Guindon GE, Cameron D, Boupha B, Dejman M, Osei EJ, et al., Bridging the gaps between research, policy and practice in low- and middle-income countries: a survey of health care providers. CMAJ. 2010;182(9):E362-72. doi:10.1503/cmaj.081164 